\title{
O PROCESSO DE DEGENERAÇÃO DOS PARTIDOS POLÍTICOS NO BRASIL
}

\author{
Tese apresentada como requisito \\ parcial para obtenção do título no curso \\ de doutorado em Direito do Estado \\ pela Faculdade de Direito da \\ Universidade de São Paulo, sob \\ orientação da Professora Associada \\ Mônica Herman Salem Caggiano.
}

Universidade de São Paulo

Faculdade de Direito

São Paulo 


\section{AGRADECIMENTOS}

Antes de tudo, externo minha imensa e renovada gratidão à Professora Associada Mônica Herman Salem Caggiano, que, generosamente, aceitou o enorme encargo de orientar-me e conduzir-me durante esta nova pesquisa, tendo-o feito, não obstante, com a segurança, rigidez e compreensão típicas da notável guia que é. Devo-lhe, sem qualquer sobra de dúvida, mais este o modesto progresso científico.

Agradeço, ainda, pelo privilégio de ter sido examinado pelo Professor Manoel Gonçalves Ferreira Filho, que, também no pantanoso campo do estudo dos partidos políticos sob a ótica jurídica, foi pioneiro entre os grandes juristas brasileiros nos idos tempos em que estes, na correta acepção da expressão, eram mais comuns.

Pela análise cuidadosa do trabalho e pelos comentários, dicas e observações edificantes tecidos acerca dele, minha gratidão se estende integramente à Professora Doutora Nina Beatriz Stocco Ranieri.

Aos demais professores que comporão a banca examinadora também agradeço de antemão.

Aos amigos, novos ou já antigos, do trabalho e de fora dele, Auro Augusto Caliman, Estevão Horvath, Fábio Augusto Martins Lepique, Glauco Silva de Carvalho, Helio Michelini Pellaes Neto, João Francisco Aprá, João Monteiro de Castro, Marcelo Passamani Machado, Nelson de Almeida Prado Hervey Costa, Rubens Naman Rizek Junior e Tiago Pereira Pimentel Fernandes, meus sinceros agradecimentos pelo apoio constante, mesmo diante da ausência, e pela companhia insubstituível nas trincheiras acadêmica e da vida.

Ao Professor Cláudio Lembo e a Guilherme Afif Domingos, meu honesto apreço e dedicada gratidão por toda a confiança em mim depositada e por todas as oportunidades oferecidas. A convivência com ambos têm sido uma escola insubstituível.

Finalmente, à Roberta, pelo amor, paciência e incentivo incondicionais, apesar das tantas e tantas horas que nos roubei durante os cruciais meses finais da empreitada. 
Aos meus amados pais e irmãs, meus primeiros, mais constantes e incondicionais incentivadores 


\section{RESUMO}

Este trabalho é dedicado à análise do fenômeno partidário brasileiro. Mais especificamente, apresenta maiores detalhes de algumas de suas feições degeneradas e busca identificar, no ordenamento jurídico brasileiro, as possíveis principais causas normativas que expliquem este processo para, em seguida, propor alternativas possivelmente capazes de combatê-lo.

O foco do estudo é essencialmente jurídico, visto que, os partidos políticos, após longa e deliberada omissão dos legisladores (constitucionais, principalmente), desde meados do século XX, vêm afirmando sua presença nos ordenamentos jurídicos de todo o mundo. Hoje, portanto, os partidos políticos são amplamente reconhecidos como um dos principais players do cenário político e, como tal, têm merecido uma atenção cada vez maior dos juristas. Pois se o direito em geral - e o constitucional em particular - interessa-se por todos os principais aspectos que envolvem o processo de aquisição, exercício e perda do poder político dentro do Estado, nada mais natural que também passe a interessar-se em regular o funcionamento destas associações especificamente constituídas para este propósito.

Entretanto, apesar de reconhecido e regulado pelo direito legislado, o fenômeno partidário está sujeito à incidência de uma série de dinâmicas próprias que só podem ser investigadas sob o prisma sociológico ou político. Esta é uma realidade que não pode ser ignorada pelo jurista que se aventurar em apontar a necessidade de realização de ajustes normativos nas regras do jogo político.

Por este motivo, o trabalho, apesar de seu enfoque jurídico, busca na ciência política evidências empíricas que apontem para a adequação ou inadequação das normas vigentes e das propostas ao final formuladas.

O primeiro capítulo focalizará, principalmente, a evolução histórica dos partidos políticos brasileiros. O segundo enumerará algumas das principais características degeneradas de nosso sistema partidário. Finalmente, o terceiro procurará apontar as causas normativas para as deficiências encontradas e proporá, quando necessários, ajustes na regulamentação partidária, eleitoral e institucional vigentes. 


\begin{abstract}
This work is dedicated to the analysis of the Brazilian partisan phenomenon. More specifically, it presents greater details of some of its depraved features and tries to identify, in the Brazilian legal system, the main possible normative causes that explain this process for, after that, to consider alternatives possibly capable to fight it.
\end{abstract}

The focus of the study is essentially legal, since, the political parties, after long and deliberated omission of the legislators (constitutional, mainly), since middle of century $\mathrm{XX}$, come affirming its presence in the legal systems of the whole world. Today, therefore, the political parties are widely recognized as one of the main players of the politician scene and, as such, have deserved more and more attention from the jurists. Therefore, if the law in general - and specially the constitutional law - are interested for all the main aspects that involve the process of acquisition, exercise and loss of the politician power within the State, nothing more natural than also interest itself in regulating the functioning of these associations specifically constituted for this intention.

However, although recognized and regulated for the legislated law, the partisan phenomenon is put under the incidence of a special dynamic series that only can be investigated under the sociological or politician prisms. This is a reality that cannot be ignored by the jurist who ventures himself in pointing the necessity of accomplishment of normative adjustments in the rules of the politician game.

For this reason, the work, although its legal approach, searches in science politics empirical evidences that indicates the adequacy or inadequacy of the effective norms and of the proposals formulated at the end.

The first chapter will focus, mainly, the historical evolution of the Brazilian political parties. The second will enumerate some of the main depraved characteristics of our partisan system. Finally, the third will try to point the normative causes related to the joined deficiencies and will consider, when necessary, adjustments in partisan, electoral and institutional effective rules. 


\section{RIASSUNTO}

Questo lavoro è dedicato all'analisi del fenomeno dei partiti brasiliani. Più specificamente presenta importanti particolari di alcuni dei suoi aspetti degeneranti per identificare nel sistema legislativo brasiliano le principali possibili cause normative che spieghino questo processo, per poi considerare le alternative capaci di combatterlo.

Il punto focale dello studio è essenzialmente legale, poiché, i partiti politici, dopo la lunga e deliberata omissione da parte dei legislatori (principalmente costituzionali) dalla metà del secolo XX, vanno affermando la loro presenza nei sistemi legislativi del mondo intero. Oggi quindi è ampiamente riconosciuto che i partiti politici sono tra i principali attori della scena politica e, come tali, hanno meritato una attenzione sempre maggiore da parte dei giuristi. Di conseguenza se il diritto in generale - e il diritto costituzionale in particolare - è interessato a tutte le funzioni principali che coinvolgono il processo di acquisizione, esercizio e perdita del potere politico all'interno dello Stato, è naturale che esso cominci ad interessarsi anche a regolare il funzionamento delle associazioni specificamente costituite a questo proposito.

Tuttavia, anche se riconosciuto e regolato dal diritto legislativo, il fenomeno dei partiti politici è soggetto all'incidenza di una serie di dinamiche sue proprie che possono essere studiate soltanto sotto il prisma politico e sociologico. Ciò è una realtà che non può essere ignorata dai giuristi che si arrischiano a sostenere la necessità di effettuare cambiamenti normativi nelle regole del gioco politico.

Per questo motivo, il lavoro, malgrado il suo metodo giuridico, cerca nella scienza politica prove empiriche che puntino all'adattamento o meno delle norme vigenti e delle proposte al fine formulate.

Il primo capitolo metterà a fuoco, principalmente, lo sviluppo storico dei partiti politici brasiliani. Il secondo enumererà alcune delle principali caratteristiche degenerate del nostro sistema dei partiti politici. Per concludere i terzo cercherà di indicare le cause normative delle deficienze identificate e proporrà, se necessario, aggiustamenti nella regolamentazione dei partiti, in quella elettorale e istituzionale vigente. 


\section{ÍNDICE}

INTRODUÇÃO

CAPÍTULO 1 - ASPECTOS GERAIS DOS PARTIDOS

POLÍTICOS NO PANORAMA DA DEMOCRACIA MODERNA

1.1. Os partidos políticos: origens

1.2. Importância do sistema de partidos no processo de consolidação da democracia moderna

1.3. Degeneração dos partidos, declínio dos parlamentos e crise da democracia representativa: um processo endêmico

1.4. Os partidos políticos no Brasil

1.4.1. Os partidos antes de 1891

1.4.2. Os partidos na República Velha 48

1.4.3. Os partidos no período Vargas $\quad 57$

1.4.4. Os partidos entre 1945 - $1965 \quad 69$

1.4.5. Os partidos entre $1965-1978$

1.4.6. Os partidos na atualidade 93

CAPÍTULO 2 - PATOLOGIAS DO SISTEMA PARTIDÁRIO

2.1. A simbiose parasitária das patologias

2.2. A homogeneização ou amorfismo dos partidos

2.2.1. Ideologias versus programas de governo

2.2.2. O estreitamento das margens de diferenciação entre os programas

2.2.3. Os partidos catch-all: a moldagem do discurso político e dos programas de governo em busca da identidade com o eleitorado

2.2.4. Algumas possíveis conseqüências do fenômeno da homogeneização no cenário político 
2.3. Multiplicação dos partidos políticos, unidade interna e a questão dos nanicos

2.3.1. A vocação para a unidade

2.3.2. O equilíbrio: a necessidade de representação suficiente das minorias

2.4. Oligarquização das decisões partidárias

2.4.1. A personalização do voto e o fortalecimento de elites partidárias: a questão das listas e a falta de democracia interna na escolha dos dirigentes e candidatos

2.4.2. A falta de democracia interna e a coerência com os programas

2.4.3. A fidelidade partidária e seus impactos sobre as elites partidárias

2.4.4. O processo legislativo bicameral e os chefes partidários nas duas Casas

2.5. A cooptação de partidos e as alianças com o governo

2.5.1. A homogeneização, a cooptação de partidos e as alianças com o governo

2.5.2. As coligações eleitorais para o executivo e legislativo e a cooptação

2.5.3. Alguns efeitos malignos da cooptação: a alteração da vontade das urnas e a precarização das oposições

2.6. A infidelidade partidária

2.6.1. O tratamento jurídico da infidelidade no Brasil contemporâneo

2.6.2. Personalização do voto e transfuguismo

2.8.1. O fisiologismo, a patronagem e a cooptação de parlamentares e partidos 
2.8.2. A possibilidade de contaminação do resultado das eleições seguintes

2.9. A fragmentação dos partidos

2.9.1. A fragmentação interna dos partidos, o processo de oligarquização e os grupos de interesse e pressão

2.9.2. A fragmentação interna dos partidos e as sublegendas

2.10. Corporativismo

2.10.1. O corporativismo entre os indivíduos da classe política e entre os partidos

2.10.2. A legislação em causa própria - a dificuldade de aprovação das soluções propostas para o aprimoramento do sistema político-partidário

\section{CAPÍTULO 3 - OS FATORES NORMATIVOS DE DEGENERAÇÃO DO SISTEMA PARTIDÁRIO BRASILEIRO ATUAL}

3.1. Algumas limitações impostas pelas normas de estrutura de poder

3.1.1. O sistema presidencial brasileiro: a diluição da responsabilidade política entre Executivo e Legislativo: a dificuldade na identificação dos culpados

3.1.2. O federalismo tripartido brasileiro, a incerteza da repartição de competências, a contaminação recíproca dos resultados das ações de governo e a diluição da responsabilidade política entre os entes da Federação: a dificuldade na identificação dos responsáveis

3.1.3. O fortalecimento da União e o afastamento do poder do povo

3.1.4. Accountability, impunidade e educação para a política

3.2. A insuficiência qualitativa das normas eleitorais, partidárias, parlamentares e de sucessão no poder 
fragmentação das bancadas e dupla necessidade de negociação com o Congresso

3.2.2. O excesso de candidatos e a viabilidade das candidaturas

3.2.3. O malapportionment da Câmara dos Deputados, o desequilíbrio federativo no Congresso Nacional e a estrutura federativa exagerada

3.2.4. O caráter nacional dos partidos e o seu monopólio para a apresentação das candidaturas

3.2.5. Os vices e a regra de suplência no Senado Federal

3.2.6. O sistema eleitoral e a delimitação das circunscrições eleitorais

3.2.7. As coligações

3.2.8. As convenções como fórum para escolha de candidatos: a distorção das comissões provisórias

3.2.9. O colégio de líderes nos parlamentos e a oligarquização: uma realidade insuperável?

3.2.10. O sufrágio obrigatório e a participação política

3.2.11. A ausência de limitação de mandatos legislativos

3.2.12. A possibilidade de reeleição no executivo e a desnecessidade de desincompatibilização para concorrer ao mesmo cargo

3.2.13. A cláusula de desempenho e os critérios de acesso ao fundo partidário e ao tempo de rádio e televisão

3.2.14. A simultaneidade das eleições gerais e a renovação total da Câmara 